\title{
Envisioning futures: imagining technoscientific worlds in film
}

\author{
Regula Valérie Burrio
}

\begin{abstract}
Films can be seen as cultural projections of technoscientific futures. The ways that technoscience is represented in films may shape the way we perceive future innovations and the social implications of such developments. Films can thus serve as documents to study cultural perceptions of the future. This paper explores how visions of future technoscientific worlds are enacted in films by analyzing exemplary short movies that were created for the first science film festival organized with support of the German federal government within the scope of its "foresight process." By applying methods from qualitative social research, this paper discusses how the selected films represent the roles of both humans and technoscience in future worlds. Although these films each display different visions of such roles, the analysis shows that they all address the importance of technoscience in future lives and imagine that humans embrace an active role as (self-) entrepreneurs and political subjects within future technoscientific worlds.
\end{abstract}

Keywords: Future studies, Visions, Imaginaries, Science film festival, Foresight, Technology Assessment

\section{Introduction}

Science and technology have been of long-term interest to filmmakers, and similarly, scientists have used films to disseminate their work ever since film cameras have been available. Researchers of science and technology studies (STS) and science communication have examined the relationship between science and films mainly from four perspectives: representation, interaction, communication, and impact. Several studies have explored science in films by looking at ways science, scientists, and physicians are represented in films (e.g., [1-10]). Other studies have examined films in science by investigating ways that scientists interact with moving pictures in their work (e.g., $[11,12])$. The third perspective examines ways that science is communicated to a wider public by cinematographic means and how the audience understands science as presented in both fictional and documentary films (e.g., [6, 13-15]). The fourth perspective of interest refers to the impact of films on the production and development of science $[16,17]^{1}$

With the exception of studies that explicitly explore science fiction films (e.g., $[10,17,18])$, most of this

Correspondence: regula.burri@hcu-hamburg.de

HafenCity University Hamburg (HCU), Ueberseeallee 16, 20457 Hamburg, Germany

(c) The Author(s). 2018 Open Access This article is distributed under the terms of the Creative Commons Attribution 4.0 International License (http://creativecommons.org/licenses/by/4.0/), which permits unrestricted use, distribution, and reproduction in any medium, provided you give appropriate credit to the original author(s) and the source, provide a link to the Creative Commons license, and indicate if changes were made. research into science and film deals with documentaries in which actual science is first assumed to be represented in an accurate way. Even in major feature films produced by the Hollywood film industry, science consultants often are involved in the production to guarantee scientific credibility and accuracy [16]. Although STS and science communication scholars are sensitive to the ways scientific accuracy is constructed and communicated, they have not yet explored in depth how techno-scientific futures are imagined in films.

In this article, I ask how technoscientific futures are imagined cinematographically. I am interested in ways that filmmakers envision the intertwining of future worlds and technoscience and how these visions are enacted in films. By analyzing three short films that were shown at a science film festival, I explore ways that forthcoming technoscientific realities are constructed via cinematographic means. Although this perspective remains underexplored in STS and science communication literature, this article may serve also as part of a larger project to study and assess cultural visions and imaginaries of science and technology [19-21]. It can also build on studies that have explored images of the future in films more generally, regardless of science [22, 23].

In the section "Context and methods," I briefly describe the film festival where the films analyzed in this

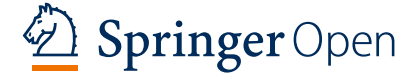


article were screened and specify the methods used for analysis. The third section introduces the three short films selected and examines how they imagine future roles of humans and technoscience. In the subsequent section, these visions are reconsidered and compared. This section also discusses the commonalities of the revealed sociotechnical imaginaries that point to possible space for reflection, action, and resistance toward future technologies and the specific societal conditions under which new technologies emerge. The conclusion relates the findings to cultural imaginaries and reflects on how film analysis can contribute to technology assessment (TA) and foresight studies.

\section{Context and methods}

\section{The Foresight Filmfestival}

The first Foresight Filmfestival took place in Halle, Germany, on July 2, 2015. With the theme, Science Meets Vision, the film festival presented a number of short films that were about foresight issues. The festival was organized by the local university in cooperation with "science2public," a local science communication organization and the renowned Fraunhofer Institute for Systems and Innovation Research (ISI). ${ }^{2}$ The Foresight Filmfestival was supported by the Federal Ministry of Education and Research (BMBF), which plays a key role in foresight research in Germany, in order to communicate the results of the so-called "foresight process."

The self-declared aim of the festival was to bring science and society into dialog in order to debate "where the journey should lead" ([24], translated by the author), especially with regard to the rapid development of technological innovations and their societal impacts. The festival received significant attention from the media, partly because important German media outlets served as cooperation partners for the festival, thus facilitating media coverage. In addition, the organizers were active participants in social media. ${ }^{4}$

The festival competition topics drew from some of the issues identified in the BMBF foresight process. The public call for submissions that was addressed to filmmakers and scientists asked for short films on the following three topics ([24], translated by the author):

(1) Self-Optimization, or The Quantified Me: How Successful, Beautiful, Happy, and Healthy Can One $\mathrm{Be}$ ?

(2) Artificial Intelligence, or The Working World of Tomorrow: Computers, Robots, and Human Creativity

(3) Post Privacy, or Where Does the Data Flood Lead Us? Of Treacherous Toothbrushes and the Oil of the Information Age.

The festival's call for entries also included requirements. In addition to adhering to the thematic framework, the submitted films were expected to be both visionary and scientifically grounded. The festival would offer creative minds "a platform for sharing their vision of how technology should develop and affect our lives in the next 10 to 20 years .... not, of course, without scientifically substantiating this vision." The call required that the short films should run a minimum of $30 \mathrm{~s}$ and not be longer than $2 \mathrm{~min}$. In addition, it promised that the winning film in each of the three subject categories would receive an award and prize money of 3000 euros. ${ }^{5}$

In order to facilitate the production of short films, the festival organizers offered free participation in the science2movie-Academy, which was targeted mainly to students. In this academy, students were coached and supported by experienced filmmakers and media experts. Twenty students from different disciplines participated in this practice-based training that began in spring $2015 .^{6}$ The call for entries, however, did not target students exclusively but also "researchers, filmmakers, visionaries," in other words "people who produce knowledge and further developments" and people "who transfer this knowledge and examine its impacts creatively" [25]. The nearly 50 films that were submitted to the festival thus originated from a variety of authors, including researchers, journalists, and filmmakers [24]. Slightly fewer than half of the films were produced at art, film, design, and media schools/colleges or respective university departments, about a quarter of the submissions originated from academic science departments, and the remainder came from other organizations, such as small media production companies. The great majority of the film creators were based in Germany.

The three subject categories of the festival did not receive equal attention by the participants. Approximately one third of the films were submitted in the SelfOptimization category, more than half in the Artificial Intelligence category, and only a sixth in the Post Privacy category. A few films were submitted in two categories. All submitted films were made available online to an interdisciplinary jury prior to the festival. The jury included 22 members (including myself), ranging from filmmakers, producers, and journalists to social scientists and foresight experts to a computer scientist. ${ }^{7}$ By applying the criteria provided by the festival organizers-thematic reference, innovation potential, scientific accuracy, creativity and originality, communication competence, balanced representation, and esthetic quality-the jurors voted online prior to the festival for the five films that they considered best in each category. ${ }^{8}$ Only the films that were selected by the jury were shown at the festival.

On July 2, 2015, around 300 people gathered in the Studio Halle location for the festival [26]. After a welcome by officials and an introduction by the head of Volkswagen's future research unit, the selected films were screened by the audience. Each category was 
introduced with a "speed talk," which was a short podium discussion conducted by two experts. Audience members were invited to vote for their favorite film in each category. Simultaneously, the films were made available online so that online viewers could vote on a webpage. Thus, public audiences were able to vote for their favorite films on site and online. The festival also featured a complementary program that included an exhibition and book table with literature about the festival's theme. The evening ended with an awards ceremony, followed by an informal party. The winning films were all produced either at art schools or a university media department. Scientists were not among the winners.

\section{Methods}

In this article, I examine how three of the films presented at the festival imagine the future. I am especially looking at ways that technoscience is envisioned to be intertwined with forthcoming worlds. To explore this perspective, I conducted a qualitative interpretive inquiry [27] by drawing on three sample cases (films), which I analyzed in terms of content, narration, and film esthetics. I selected the three films based on the criteria for the festival's three thematic categories and based on the expectation that the films would enact a maximum variation of visions. I determined such variation not from the different thematic categories but rather from an STS view (e.g., [28]), i.e., based on the ways that technoscience and humans are represented in the films, which constituted analytic categories of interest for the in-depth interpretive work. ${ }^{9}$ This analysis is not representative in statistical terms. Rather, its objective is to offer insights into ways some exemplary festival films envision future technoworlds.

As an invited jury member of the Foresight Filmfestival, I had access to all the films submitted, which allowed me to gain an overview of the films and conduct a brief analysis of both the number of submissions and the film producers (as described above). The jury task also enabled me to gain insight into the different visions of the future represented in the films. As a jury member, I received a CD with all the films presented at the festival, which served as my source of analysis, although the films also were accessible on YouTube (retrieved June 16, 2018). Apart from the mentioned sources, all other documents used in this article are publicly available online.

By applying methods from qualitative social research, the following analyses discuss how the three festival films envision future worlds. To facilitate each analysis, I first prepared a transcript of the film's audio tracks and image traces, which served as a source for the interpretive work (German audio tracks were translated). The following sections explore how the films construct forthcoming technoscientific worlds by reconstructing their contents, narrations, and cinematographic styles.

\section{Analyzing visions}

The films shown at the festival discuss future techno-scientific worlds in different ways. Either they focused on science-in-the-making by looking at how science will be produced in laboratory work a few decades from now or they dealt with ways technoscience will impact our daily lives in the future, for example by exploring how we will work and interact with other humans and technoscientific artifacts a few years from now. To discuss these subjects, the films employed a variety of cinematographic styles, ranging from animation and fiction to films that mix a variety of genres, including documentary features. The following sections provide in-depth analyses of the three selected films.

\section{Malu (film 1)}

The film malu was submitted in two categories, Self-Optimization and Post Privacy; however, it was shown only in the latter category. It was made and co-produced by Felix Brokbals, a student from a local art school, who also wrote, filmed, directed, and edited it. malu is a mixed-media film that employs both feature film images and graphic elements. The film discusses big data and human enhancement, which can be considered as two of the most prevalent subjects concerning future innovation in technoscience. The film looks at current developments in sensor technology and the design of smart devices, and projects how such technoscientific applications may shape our daily lives in the future.

In the style of an advertising film (or commercial), malu is presented as a wonderful new system that consists of three extensions-manus (hand), lumen (eye), and auris (ear)-which take the form of a nanochip implanted in the wrist, a multimedia contact lens, and a sound device, respectively. The film narrates three stories that incorporate daily situations of different actor groups: children and a jogger, a family, and a young man and woman who are just getting acquainted with each other. The film begins, however, with an introductory segment that shows a long shot of three children, two boys and a girl, playing bocce in a park. The boys hold a blue ball and a yellow ball in their hands, whereas the girl is throwing her red ball. The next shot is a point-of-view shot of the girl: She sees her ball approaching the goal. In a small, digital, transparent window to her right, she follows in real time the changing distance between her ball and the balls already bowled. The displayed numbers are changing rapidly. The digital window displays whose ball is actually leading. We get to know the names of the children: Eva, Max, and Johnny. 
Throughout the film, a female narrator, accompanied by cheerful music, is praising the advantages of malu. We now hear her saying, "With manus, lumen, and auris from malu, the world is a playground where your imagination knows no boundaries. A playground for those who follow their own paths." In the background, still from Eva's perspective, we see a jogger running by. The subsequent long shot of the first story shows a close-up of the jogger, followed by a point-of-view shot of his path. Again, we see the small digital window in which he can trace his pulse rate and topographical position. The voice announces, "The manus extension in the wrist checks vital signs in real time. The lumen contact lens shows it instantly in the head-up [digital] display." The digital window now displays an incoming message, a picture of the jogger's grandmother (at least we assume that is her identity), holding an apple pie in her hands, and subtitled with the text "coffee and cake at our place at 3 p.m." We now see the grandmother taking the apple pie out of the oven and dredging powdered sugar on the pie, thus following the indications in the transparent window. The voice says: "If everything goes by itself, and you use every moment as you want, then that is freedom."

The next point-of-view shot is from the jogger's view after having visited his grandmother. We see a young woman in the park approaching, and the transparent window reveals personal information about her, such as her name, age, profession, hobbies, and relationship status. Seemingly after a single eyelid movement, or perhaps just a thought, the window confirms that this "contact is saved." The window then reminds the jogger to call Alex and now shows the so-called Active Noise Canceling feature. The phone rings and Alex says "Hi" while the narrator advertises, "Extend the boundaries of this freedom with the auris earpiece. You only hear what you really want to hear."

The second story looks at daily family situations. We see a father with his little boy, sitting on a bench in front of a house and eating ice cream. The digital window in the subsequent point-of-view shot of the father indicates "measure blood sugar." The numbers are calculated and confirmed with a checkmark. "Keep track of what's best for your health with malu healthcare applications," the narrator suggests, "so you have more time for the important things in life. Moments that you can share with your loved ones anytime and anywhere." The father looks at his son and, through a graphic element in his view, takes a picture of him and shares it. We now see the mother sitting at home and receiving the picture in her digital window, subtitled with a chat conversation in which the father suggests that they go out for dinner. She agrees, and we see a curve chart in the window and hear the narrator: "malu helps you find the perfect balance between leisure and work. And all at once, appointments manage themselves intuitively." The next close-up shows the couple sitting in a restaurant, followed by a point-of-view shot of the mother with the digital window displaying the bill. The voice says, "And the best thing is malu does not cost you a cent. When you have to pay for something, malu Cashless Pay does the complicated part. Quick, easy, and safe." We see the mother's left wrist resting on a paying device that the server has brought to the table. A checkmark in the digital window confirms that the payment is completed.

The third story begins with a shot of a roof party, with a young man and young woman in conversation in the foreground. The next point-of-view shot of the woman provides personal data about her dialog partner, Max B., 25, single, interests: music and photography, and so on. This information is displayed in English, whereas in Max's window that we see in the subsequent point-of-view shot, information about the woman is shown in German: Nari H., 24, student, single, interests: design and music, and so on. "When strangers become friends, you enjoy the freedom of unlimited communication," the narrator praises, and continues, "The world knows 7,000 languages. And you speak them all, no matter where you are, with Simultaneous Translation." We then see a long shot of the party guests, followed by Max's view of Nari. In his transparent window, a list of selections allows him to change the pictorial style of what he sees. "It is your world, so dive it into your colors. And fill it with your passion," the narrator invites. Max, after having chosen a color for the view, takes a picture of Nari. The final shot shows happy party-goers, each one holding a sparkler. The narrator summarizes, "Be malu, be human".

\section{Analysis}

By using the cinematographic style of a commercial, the film does not reveal at first if the malu system is real and evidence-based or not. It is difficult for the audience to know if such smart devices already have been developed in a science laboratory and are now combined in a new commercialized system or if they are merely the result of the filmmaker's imagination. Some features seem to be real and are even well known based on current smartphones, such as the ability to save contact information, display recipes, receive reminders to call a friend, coordinate meetings, and pay wirelessly. Other more adventurous features that we may have heard about, such as a contact lens to measure blood sugar, already have been developed by Google [29]. The beautiful new world displayed in the film thus seems to be somehow real-if not now, then at least in the very near future. Only one small element at the very end of the film gives us a clue as to its reality. During the credits, the narrator says, 
"malu is a nonprofit project and is supported by, among others, the German Federal Office for Infrastructure Analysis and the American Association for National Security and Public Infrastructure." This statement is visually enforced by three logos: one that advertises the product, malu, and the other two that represent German and American official entities. Here, it becomes evident, at least for viewers who are familiar with German and/ or American political systems, that this information is fake, because such official departments do not exist.

Nevertheless, from a second and more analytical view, the film is not merely an invented science fiction but is based on mostly existing technoscientific applications that are projected onto the near future. The film does not decide whether this future is wishful or terrifying. The audience is seduced by beautiful pictures and the pleasant female voice and is somehow drawn into this exciting new world, yet left alone to judge the merits of this near-future, possible world.

Depicting humans In the world depicted in the malu film, humans are presented as both individualistic beings and social beings. By highlighting the possibilities of the malu system to help people make choices and decisions, the film points to the human as an individualistic being who pursues his or her individual self-fulfillment. malu is described as a "playground for those who follow their own paths" and thus offers an opportunity to pursue individual goals and allow subjective preferences, tastes, and moods. It enables the user to, for example, "only hear what you really want to hear", as the narrator explains, and shows that the system allows the user to make decisions about emotional perceptions of the acoustic environment. Depending on one's preferences, the world thus can be made available accoustically in a selective way: "You decide," the accompanying website states. ${ }^{10}$ With its "almost endless possibilities to design your world," the system is viewed as a tool to create one's life and environment. "It is your world, so jump into your colors," the narrator encourages. The individual is invited to create his or her own environment.

At the same time, the human is also considered as a social being who relates to others. In the movie's pictures, all of the people are shown as being involved in social networks and relationships. Family, friends, and other social relationships are considered to envelop people with whom special moments (such as being with one's little son eating ice cream) can be shared and are "the important things in life". Emotions and intuition, which are important characteristics of a social being, are also addressed in the film when, for example, the narrator invites the viewer to fill his or her world "with your passion".

The individualistic and social human being is imagined as someone who is striving to optimize his or her life in manifold ways. Such improvements include, first, personal health. "Keep track of what's best for your health," the narrator suggests. The film shows how the healthcare-related applications of the system instantly measure and evaluate vital signs, thus allowing the continuous monitoring of medical status and bodily conditions. This ability would transform everyone into his or her "own doctor" and enable people to "enjoy a healthy life without discomfort," as the accompanying website claims, thus promoting the improvement of health as a goal that must be achieved. This view is supported by the image of the jogger running through the park and the website stating, "Maximize your training success."

The second focus of optimization is personal work and life balance. The human is seen as struggling to "find the perfect balance between leisure and work," and malu is advertised as being able to help achieve this aim by supporting an intuitive management of appointments. Finally, the improvement of life also concerns daily activities via simplification. The system would take away "the complicated part" and make the Cashless Pay application, for example, "quick, easy, and safe."

In addition to wanting to optimize his or her life, the human is seen as someone who pursues freedom. Freedom is defined as both achieving goals and taking advantage of opportunities. "You set your personal goals and will achieve them by the shortest route," the website claims, thus imagining a target-oriented user. The achievement of goals implies freedom; the film insinuates: "If everything goes by itself, and you use every moment as you want, then that is freedom." Freedom includes, in the description of the website, taking advantage of opportunities: "[Take] your chances whenever you want. That is freedom." This directive includes, for example, the "freedom of unlimited communication".

The role of technoscience Technoscience is a central feature in the malu film. It is tightly interwoven with the world: "A world in which smart devices integrate into your life naturally is a world with malu."11 Technoscience is seen as the connecting link among self, others, and the environment, as becomes evident on the website: "Invisible and always at your side, malu builds bridges between you, your friends, and the whole world." As a consequence of this mediating function, technoscience is viewed as being able to shape and enable social relationships. It serves to connect with people and to communicate and interact with them. This feature is illustrated in the film by children playing, a grandmother inviting her grandchild to eat an apple pie, spontaneously meeting someone in the park, a couple communicating about their son and going out for dinner, and young people gathered at a party.

Technoscience is thus associated with positive feelings. It offers opportunities to design and shape the world 
according to subjective preferences and in creative ways. It allows new experiences and new knowledge by exploring skills and transgressing boundaries: "Discover unexpected possibilities of creativity and find the courage to cross borders and go new ways," the website states. This obviously optimistic world and utopian view of future technoscience, however, are disrupted at the end of the film when we are informed of the "official" supporters that are clearly fake entities. By reconsidering the film and its views of technoscience, implicit criticisms and a rather dystopian view of future technoscience are revealed.

The first criticism refers to the capitalist logic that is intrinsic in the world in which the technoscientific system, malu, is established. Even though malu is declared to be a non-profit project that "does not cost you a cent," the film offers two hints that challenge this declaration and point to a subtext in the film's vision. On the one hand, "non-profit" is displayed in the end titles along with fake governmental support organizations. We can thus assume that this declaration is meant to be false, too. ${ }^{12}$ It points to digital technologies that are available for free, but in reality, are paid for in the form of data that people deliver when using such apps and tools. The malu system, the film insinuates, is part of this data economy, which is ultimately driven by the desire for profit. On the other hand, malu is promoted in the form of an advertisement. Advertising films are aimed at selling products to make a profit. This filmic genre is thus inherently coined by capitalist logic. For this film, the advertising genre was chosen deliberately and can be interpreted as emphasizing the for-profit idea behind the marketing of self-optimizing technologies.

The second and central criticism put forth by the film concerns the potential risks of such technoscientific applications. Privacy may be endangered when humans, technoscience, and the environment are closely intertwined by the use of smart devices. The production and collection of personal data raise questions about who will own and have access to these data and the kind of impact this phenomenon will have on individuals. The vision offered in the film also points to the problematic nature of the social implications of innovations that are designed to optimize our lives. Such innovations may become a societal imperative, thus making them impossible to avoid and reject in the future.

\section{Quantified Love (film 2)}

The film Quantified Love was submitted in the Self-Optimization category. It was co-produced by $\mathrm{Su}-$ sanne Csik and Wassili Bloch, written by Robert Martin, and directed by Stefanie Spachmann at a private film school called filmArche Berlin. This feature film, which includes graphic elements, explores human enhancement by focusing on health-monitoring technologies. It discusses the impact of these technologies on the life of a couple who wish to have a baby.

In the first scene, we see a young woman jogging in a park. She looks at the screen of a smart device, which is also shown as a graphic element in the image. The "Healthy Living Index" with a real-time calculation is displayed on the monitor as well as the name of the jogger, Lana Siewert, and three icons marked in green: a person in motion (value 82), a bottle (value 100), and a smiley face (value 82 ), which symbolize exercise, nutrition, and well-being, respectively. The next scene shows Lana sitting with her partner in a doctor's office. She takes a sip from a bottle that we recognize from the icon. The screen of her health device is displayed on the wall. "Bravo, Ms. Siewert," says the female physician sitting opposite them at the table. "Your HeLI [Healthy Living Index] is at an excellent 95 percent. Go on like that." Then, the doctor addresses Lana's partner. "If your index has a similar optimum value, nothing stands in the way of your wish to have a child." The couple look happily at each other, and the physician asks the partner for his NutriPlus. He holds his left wrist over a screen that is lying on the table. The results and his name, Phius Kreigel, as well as a chart showing his "ethylglucoronide/alcohol" blood level are displayed on the wall. The chart covers the days Monday through Thursday. The physician becomes alarmed and reproachful: "A striking eruption of ethylglucoronide (...) sometimes even in the afternoon. What's the matter with you, Mr. Kreigel? Almost no alpha-CEHC-glucoronide, and what really worries me is this significant amplitude of lathosterol." The screen on the wall shows a chart of "lathosterol/fast food" with an upward curve. Lana becomes frightened and looks at him questioningly: "Is this correct, Phius? This cannot be correct. You always drink your Opti-Nutri." Hopefully, she turns to the physician: "Could the NutriPlus perhaps be defective again?" The doctor shakes her head, and Lana adds: "Well, then I may need to look for another father for my children." We see a graphic display that shows Phius' Healthy Living Index decreasing from 40 to $18 \%$, and the smiley face dropping to 8 , while the nutrition icon also indicates the low value of 8. "You are making the right decision, Ms. Siewert," the physician says.

In the final scene, we see Lana jogging in the park again. Her device reveals that her Healthy Living Index has declined to $72 \%$. Although both her exercise and nutrition values are excellent, her smiley value falls to 45 and turns from green to red.

\section{Analysis}

The film demonstrates the potential impacts of self-optimizing technologies on our lives and well-being. 
Through its cinematographic genre of a feature film, it is obvious to the audience that the film does not necessarily depict reality. Nevertheless, the future world shown in the film is not mere fiction. Like in the first film, we already are familiar with similar monitoring technologies from smartphone and smartwatch applications. Functional food and drink that are aimed to improve our health, as represented by the bottle that appears in the film, can be bought in any supermarket today. Also, fitness bracelets are promoted in numerous advertisements. As in the first film, malu, Quantified Love also draws on existing technoscientific applications and imagines how these apps may impact us in the very near future.

Depicting humans Humans in the Quantified Love film are imagined as highly adaptive to the environment. Different from in the first film, their individualism does not primarily serve their self-fulfillment but rather satisfies the need to comply with scientific and technomedical requirements and related societal expectations. In the world imagined in the film, everyone is expected to work to improve themselves. Exercising, depicted as Lana jogging in the park; eating well and in a personally optimized way, as exemplified by the Opti-Nutri in Lana's bottle; and abstaining from alcohol to avoid a negative mutation of one's blood levels will be daily future tasks of humans, as projected in the film. Only by complying with these expectations, the film seems to claim, will people be able to pursue well-being and happiness. Furthermore, these behaviors are continuously monitored and quantified. The goals are not set individually (seemingly) according to one's preferences and taste, as is the case in malu, but are defined externally by science, medicine, and society, and are inscribed into smart devices. The physician compliments Lana for having achieved a HeLI of $95 \%$, thus revealing that this percentage is considered a very good value according to science and not as a subjective mark set by Lana.

The quantification of goals involves humans being subjected to competition. "If your index has a similar optimum, nothing stands in the way of your wish to have a child," the physician says to Phius, thus immediately comparing his values with Lana's. Phius is expected to keep up with Lana and perform in a similar way. The striving for improvement and perfection includes the progeny, and the potential parents thus are obliged to pass on optimized values to their child.

Achievement of the goals is both self-monitored and externally controlled by the expert and the technoscientific applications. The physician can be viewed as only one representative of science and society. It is science and society that finally control the individual's behavior. If humans do not comply with the expectations, the film suggests, they will suffer from consequences, such as the break-up of a relationship and a decrease in well-being and happiness. Humans are thus shown as social beings; however, love and relationships are quantified when they are subordinated to optimization.

The role of technoscience Technoscience is shown in the film as being intertwined with humans and their bodies. It serves to support their optimizing practices to reach their goals, which seem to be voluntary but are also imposed on them. However, technoscience also shapes social relationships by allowing numbers and values to become important figures that serve humans as guidance and orientation for their lives. Technoscientific applications are used to monitor daily activities such as moving and eating, which makes the control of individual behaviors, both individually and externally, possible.

Although Quantified Love projects a world in which technoscience helps people to live a healthier life, if they are just willing to do so, the film implicitly raises critical questions about the implications of such technoscientific innovations. As in malu, emerging societal norms that force people to optimize their lives can become problematic. If everyone improves his or her capacities, societal expectations are pushed toward becoming rigid norms. Such expectations may be imposed harshly, and resistance is difficult and accompanied by consequences such as difficulties in the job market and increased health insurance fees. Implicitly, the film asks about the quality of such a lifestyle that sacrifices subjective happiness for the desire for perfect health. The film also shows that we must necessarily fail to reach perfection.

\section{New Bees (film 3)}

The film, Greenpeace-New Bees, was shown in the Artificial Intelligence category. This film had not been produced exclusively for the Foresight Filmfestival, but was commissioned by Greenpeace and released the year before the festival. With Paris-based Alexander Kalchev as its creative director, the short film was directed by a Berlin collective of filmmakers called Polynoid and was produced by the Berlin production companies Woodblock and Soilfilms. New Bees uses both feature film images and animation. Made in the style of an English-speaking advertising film, it depicts a world in which robot bees have replaced natural pollinators.

The film opens with images of a hayfield with a pasture, flowers, and rustling wind, while light music plays. A female narrator recounts: "Five years ago, these fields were a barren wasteland. Honeybee colonies were collapsing, and pollination had all but stopped." The music becomes dramatic and the voice continues: "But all of this has changed now. Because bees are back." We see bees flying around the hayfield. "But wait." Then a deep 
metallic noise is heard. "What is this? You might think these are ordinary bees. But let us take a closer look. These little marvels of advanced robotics are second-generation New Bees." Several black, metalliclooking robots in the shape of bees are approaching and landing on the flowers. The voice says, "Far superior to their natural counterparts, they have been successfully implemented all over the world. Completely solar-powered, a New Bee requires very little down-time to recharge. Using real-time triangulation technology, each New Bee knows which part of the field has been pollinated, maximizing efficiency and yield."

The next images show close-ups of a big insect approaching the bees on the ground. The voice explains: "Unlike standard bees, New Bees are fully equipped to fight their natural enemies. As soon as a predator approaches, the New Bees are alerted, release a fast-acting insecticide, and neutralize the threat in a second. Nothing can harm them." The predator turns over on the ground, makes some final twitches, and appears to die. As we are shown the hayfield again, the voice adds: "New Bees do not tire, require minimum maintenance, and are produced for a fraction of the upkeep cost of normal bees. They are easily recycled, replaced, and activated." The images now show a boy and girl playing in the hayfield. "New Bees blend in perfectly with nature and are programmed not to harm us," the voice praises. A bee lands on the arm of the girl and she observes it. The voice concludes, "Soon you'll be able to purchase a new colony and activate it in your fields. New Bees - the future is already here." The last take-up shows the two children.

\section{Analysis}

New Bees was not developed as a science fiction film but presents at first sight as a seemingly realistic view. Although the viewer realizes that it is a film that is advertising robot bees, the viewer requires knowledge about state-of-the-art technoscience to understand whether the film is based on existing innovation or is a dystopic vision of how we will maintain our ecosystem in the future. As many people are aware of the real potential extinction of bee colonies and have heard about advances in robot science, robot research could indeed possibly have achieved small flying robots that are able to distribute pollen.

Unlike the first film, malu, the credits do not provide a clear answer. Rather, they display several logos of large, real companies, such as BASF, Syngenta, Bayer CropScience, Monsanto, Dow AgroSciences, and DuPont. The subsequent image shows the text "Google search: robot bees," followed by a question: "Should we create a new world or save our own?" and the appeal to "Act now on SOS-BEES.ORG."
The viewer might think that the mentioned companies have sponsored the film, and the message to search Google for "robot bees" as well as the appeals may enforce the viewer's consideration that such robot bees could indeed exist. Only after following the suggestion to search the internet for "robot bees" does it become evident that research into such robotic bees is ongoing. The film's creative director, Alexander Kalchev, confirms: "There was very little to invent and although I deliberately styled it as a dystopian sugar-coated commercial funded by pesticide companies, the content is very real." ${ }^{13}$ Inspired by an article about Harvard scientists who had succeeded in creating the first basic prototype of mechanical bees, Kalchev says that "the film wrote itself" and worries that the future will be "[p]otentially much worse." ${ }^{\text {N }}$ New Bees is thus not science fiction but based on prototype technology. The film does not project its own vision but rather presents the vision of scientists who use artificial intelligence to address the real problem of dying bee colonies. In short, New Bees is not a science fiction movie but offers a potential near reality. As the film concludes, "the future is already here."

Depicting humans With the exception of the two children playing in the hayfield and the narrator, no humans appear in the film. The boy and girl symbolize the future. They do not fear the robot bees, which, as we are told, "are programmed not to harm us." Rather, the children are curious and open-minded about the robots and calmly observe what they do. Instead of humans, the main actors of the film are the robot bees. Nevertheless, humans are implicitly present in two ways. First, humans are viewed as the main originators of the disappearance of bee colonies. Although not addressed in the film explicitly, the looming extinction of natural pollinators is seen mainly as a consequence of human behavior. The website mentioned at the end of the film, which turns out to be run by Greenpeace, states: "Pollinators cannot escape the various and massive impacts of industrial agriculture." ${ }^{15}$ In an accompanying report that can be downloaded from the website, honeybees and wild pollinators are portrayed as victims of pesticides, herbicides, land-use intensification due to industrial farming, and climate change ([30]: 15-18). It is humans who use industrial agricultural practices and play an active role in climate change.

Second, humans are at the same time viewed as those who are responsible to act. They are the addressees of the appeal at the end of the film to "act now" in order to make a positive change, which means, in the view of the film's initiator, to move toward ecological farming [30]. Although almost absent in the film's images, humans are thus ascribed a double role as both originators of the changes in the ecosystem and persons responsible for 
protecting the natural balance. The question, "Should we create a new world or save our own?" that is shown at the end of the film, is merely rhetorical.

However, not all humans are treated the same way. The list of the large agroindustrial companies at the end of the film points to the perception of these actors as the main originators of the environmental problems that have caused the disappearance of bee colonies, whereas the appeal to "act now" addresses the film's viewers as responsible citizens.

The role of technoscience Technoscience is promoted in the film as the solution to a crucial ecosystem problem. Since the "collapse" of bee colonies, the voice insinuates, fields have become a "barren wasteland." However, due to the arrival of the robot bees, the voice claims that "this [situation] has changed now." The solar-powered artificial bees are portrayed as being able to take over the task of natural pollinators. From this viewpoint, technoscience is a substitute for nature. Yet technoscientific applications are not presented as an enemy of humans because the robotic bees are "programmed not to harm us." Robot bees are described as a potential risk only for animal predators. The objective of the artificial bees is to fulfill pollination tasks and thus contributes to maintaining the balance of the ecosystem.

The film, however, challenges this positive vision by its suggestion to google "robot bees" and obtain information about this innovation. The viewers are encouraged to reflect if they should "create a new world or save our own?" The film thus serves to invite debate. Although it does not take an explicit position, Greenpeace's related information campaign provides a clear answer: Industrial agriculture that deploys aggressive chemicals may lead to a collapse of the ecosystem. The solution to the problem is seen not as new artificial intelligence but rather ecological farming.

The film also points to the intrinsic links between industrial agriculture and capitalism when it points out the low cost and high efficiency of the robot bees: They "are produced for a fraction of the upkeep cost of normal bees", "require minimum maintenance", and need "very little downtime to recharge", thus "maximizing efficiency and yield". They are thus in alignment with capitalist requirements.

\section{Imagining futures}

The analyses of the three films reveal specific visions that include the future roles of both humans and technoscience. The analysis discloses particular "sociotechnical imaginaries" [20], which are public performed visions of desirable futures. These imaginaries are "animated by shared understandings of forms of social life and social order attainable through, and supportive of, advances in science and technology" ([31]: 4). Although basically collectively held and institutionally stabilized, sociotechnical imaginaries "can originate in the visions of single individuals or small collectives" ([31]: 4). The imaginaries that emerge from the analyses of these three festival films can be described by exploring perceptions of the role of future technoscience, including the expectations and the gains and risks associated with future technologies, and the ways that society's role in technoscience and the governance of risks are envisioned. I discuss these features by summarizing the findings from the film analyses.

\section{Technoscience: enabling, monitoring, and substituting}

The role of future technoscience and the imagined expectations regarding gains and risks are framed differently in each of the three films. In the first film, malu, the technoscientific applications are shown as devices that enable humans to enhance their possibilities and opportunities and shape the world according to their preferences. Technoscience is pictured as intrinsically interwoven with humans' lives and bodies. It is seen as beneficial because it amplifies human experience, enriches and enables social relationships, and makes lives easier. Technoscience is thus framed as progress and not as a threat, although the film implicitly points to the capitalist logic involved in this progress and suggests that viewers consider its potential risks in terms of privacy and potential societal pressure.

The second film, Quantified Love, imagines the future differently. Although technoscientific applications can improve human conditions and are linked with the human body in the film, they serve also to monitor and control human activities. In the film, Lana monitors her Healthy Living Index when jogging in the park, and the physician monitors and controls her data that are displayed on the wall. The physician can be seen as representing society. She imposes medical expert knowledge upon Lana, which at the same time is expressed in terms of societal expectations and norms with which an individual must comply. Both Lana and the physician-or, the individual and society-are actors with a potentially common interest in monitored activities and collected data. Technoscientific applications can serve as guidance for human behavior but at the same time control this behavior and make it adapt to social norms. In that sense, technoscience is viewed as a force that is capable of subordinating humans, a force that is implicitly challenged in the film. Both societal norms and imperatives as well as lifestyles that give self-optimization priority over happiness are questioned in the film and presented as potential perils of future technoscience.

In the third film, New Bees, technoscience is not viewed as an instrument to enhance and alter human behavior 
but rather as an independent actor that is not necessarily closely related to humans. Although created by humans, a New Bee lives its own life. The artificial robots are described as replacements for natural pollinators and thus as contributors to the maintenance of the ecosystem. Technoscience is thereby imagined as seemingly able to substitute nature. It is advertised as being even superior to nature, because artificial bees, in contrast to natural pollinators, are more efficient and never tire. However, by suggesting that the viewer make further inquiries about the issue and by delivering additional information, the film offers up this vision for discussion. The website mentioned at the end of the film, which points to Greenpeace's related information campaign, addresses the risks of the use of chemicals in the agroindustry and suggests ecological farming instead.

\section{Humans: creating, complying, and acting}

From the perspective of STS, society consists of intertwined networks that include humans and non-humans [32]. In this study's analyses, I focused particularly on two main elements in such networks: technoscience and humans. The selected films envision the future role of humans in various ways.

The first film, malu, calls for the creative use of technoscience. By making constructive use of new techno-scientific possibilities, the film suggests, humans will be able to create their world according to their own wishes and individual aims. Depending on their own decisions, individuals will be able to reach their goals and relate to other people in multifaceted ways through technoscientific products. People are perceived as pursuing happiness and freedom by technoscientific means. They are viewed finally as taking the role of creative entrepreneurs who have the option to design their lives with the help of technoscience. Self-fulfillment, well-being, desires, and success are the drivers of their actions.

Quantified Love, the second film, adopts a similar yet still different perspective. People are not imagined as using technoscientific applications creatively but rather as using them in standardized, prescribed ways. Technoscience allows people to adapt and comply with social norms that are both inscribed in the devices and controlled and monitored by the individual as well as by external experts. The individual is expected to work continuously to improve him/herself and is thus subject to coercion. Each person has a responsibility to comply with medical requirements and social expectations and is viewed as responsible for his/her health and happiness. Humans thus are imagined as self-entrepreneurs who are expected to work steadily to improve and manage their lives.

In the third film, New Bees, humans are presented as the originators of environmental problems and as the ones able and responsible to deal with them. However, a close reading reveals that the imaginary distinguishes between agroindustrial companies as problem causers and viewers (citizens) as potential problem solvers. In contrast to the other two films, the human role is not imagined as one that looks after individual lives by designing or improving them; rather, humans are expected to reflect on past activities, take care of the environment, and act in a responsible way. Humans (viewers) are not imagined as entrepreneurs as they are in the other two films, but instead are framed as political subjects when the end titles of the film invoke viewers to "Act now on SOS-BEES.ORG." The audience is requested to resist current and future technoscientific developments in case such developments do not save nature but rather create new problems and hinder people from acting in a responsible way.

\section{Entrepreneurial selves and political subjects}

The three selected films shown at the festival include, at first impression, various sociotechnical imaginaries, which is not surprising given that a variety of visions of future worlds was one of the selection criteria of the analyzed films. Nevertheless, the film imaginaries show some commonalities. First, they all address the importance of technoscience in our future lives. Technoscience is imagined to be embedded in our future bodies or environments and to play a dominant role in the ways we will live our daily lives and perceive our social and environmental realities. Second, in a closer reading of the filmic visions, they all imply critical attitudes toward potential technoscientific developments. Although the films explicitly praise the possibilities of new devices and artificial robots, they implicitly point to problematic implications and risks that come with these technologies, thus calling on the viewer to reflect on such developments and their potential effects on humans.

Third, all of the films imagine humans taking an active role in dealing with future technoscience. On the one hand, humans are challenged as (self-) entrepreneurs. Their task is to improve their bodies and lives by means of technoscientific devices, either by using them creatively and/or by complying with social expectations. In the context of a capitalist system, individuals are required to employ their creativity, flexibility, and resources in a daily struggle to optimize themselves in order to meet the requirements of the market. They are thus becoming an "entrepreneurial self" [33], responsible for managing their lives and obliged to try to prevent potential health problems [34] by training and optimizing themselves with the help of technoscience. On the other hand, humans are envisioned as political subjects. They are imagined as being able to find solutions to environmental problems. Although the strategy to develop 
robot bees with artificial intelligence is questioned as a potential solution to an environmental problem, all three films address humans as political subjects in their call to reflect on the implications of technoscience and, in the third film, to act immediately.

The imaginaries thus unfold an open space for both action and resistance that is directed not only toward emerging technoscience but also toward the (capitalist) contexts in which emerging technoscience evolves. In both readings, humans are encouraged to do something, either in an affirmative way to adapt to the system as entrepreneurs or, as implicitly suggested, to change something about it. This understanding points to the question of responsibility, as recently discussed by STS scholars. Within the framework of "Responsible Research and Innovation" [35], stakeholders involved in the research and development of technological innovations are asked to act responsibly. The analyses of the three films revealed subtext in all three films. Malu lists (fake) state departments at the end of the film, thus pointing to the governmental role in advertising the product. Quantified Love reveals the imposition of scientific knowledge and societal norms on people. New Bees points to agroindustrial companies as key triggers of environmental problems and targets the viewer as the one in charge of taking political action. All three films imagine both citizens (users, viewers) and societal institutions (government, companies) as responsible for the future development and risk governance of technoscience.

\section{Conclusions}

This article asks how technoscientific futures are imagined in the three films that were selected from a film festival dedicated to foresight. Interpretive readings of the films indicate that they frame the future of technoscience, including the expected gains and risks, and the role of humans in using and governing technoscience in different ways, thereby revealing a variety of sociotechnical imaginaries. These imaginaries range from seemingly optimistic views that open up manifold new options for human lives to dystopian views that imagine technoscience as providing methods to monitor and control individuals, leaving individuals with no other choice than to comply with social expectations. However, a closer look at the films suggests that humans are perceived as political subjects who are responsible for and capable of shaping technoscientific developments.

The sociotechnical imaginaries presented in these three films are informed by general cultural imaginaries. Such "folk theories" [36] are popular accounts and mythologies. Several cultural imaginaries are related to the more specific sociotechnical imaginaries inscribed in the analyzed films. The first imaginary refers to the concept of the human who is portrayed as using technological devices for subjective enhancements in terms of health, work-life balance, and social relationships. This characterization refers to the cultural imaginary of the individual pursuit of happiness. Although this vision is part of the United States' Declaration of Independence and thus is deeply embedded in American culture, it also can be seen in the context of the rise of the concept of the individual during the era of enlightenment, thus constituting an inherently Western concept.

A deeper reading of the films, however, reveals that they also point to a more complex notion of the individual who is subjected to societal norms. This view of the individual as having embodied social structures and acting accordingly and as being entangled with and governed by discursive regimes and therefore as applying particular "technologies of the self" has been described by prominent social theorists such as Bourdieu and Foucault [37-39]. Such entangled notions of the individual have become popular in cultural critiques and thus can be viewed as an antagonistic cultural imagination.

Another cultural imaginary that informs the sociotechnical imaginaries of the films refers to capitalism. The advertising and medical approval of technologies that enable self-optimization (in the first two films) and the appraisal of technologies that are able to fulfill the tasks of natural entities by "maximizing efficiency and yield" (in the New Bees film) are in line with capitalist thought. Although the product described in the first film, malu, does not have to be bought and is available for free, the self-optimization of its users serves neoliberal labor markets by making individuals fitter and more efficient, effective, and competitive. Such thought can be understood as a cultural imaginary. The subtexts of the films, however, point to current problematic implications of technologies that are advanced by mere for-profit thinking that neglects potential risks such as the misuse of personal data, societal constraints to accomplish particular norms and expectations, and environmental problems.

Ecologism is another cultural imaginary that underlies the more specific sociotechnical imaginaries of at least the last film, New Bees. This cultural narrative is related particularly to European culture. Popular accounts in this context include, among many others, that Europeans are ecology-minded. Such belief is supported by official statistics such as those found in the results of the Eurobarometer survey of the attitudes of European citizens toward the environment, which states that "Europeans continue to express high levels of concern about the environment and to see it as an issue that affects them personally" ([40]: 36).

Finally, civic participation is a cultural imaginary that needs to be mentioned here. Popular narratives in the European context underline the importance of civic participation for both civil society and the political system. 
An active civil society is viewed as one of the supporting pillars of democracies. The films call upon such engagement of citizens when they address them as responsible political subjects.

Although all these cultural imaginaries are well known, the more specific sociotechnical imaginaries of the films allude to the dominant critical mentality of our age. Nevertheless, the analyses demonstrate that such imaginaries are expressed in films, thus making films a source through which one can inquire into imaginaries of future technoscientific worlds. In contrast to science-based science and technology assessments, films allow a visualization of cultural imaginations with regard to ways that technoscience may shape our world in the future, thus providing access to a heuristic understanding of such futures.

Technology assessment and foresight studies have pointed out the importance of analyzing visions to understand the future of technoscience [19]. Such studies, however, have not focused on films as sources to conduct such analyses. As shown in this article, films are rich documents for investigating how future techno-scientific worlds are imagined. The inclusion of films in technology assessment and foresight studies should focus on two aspects [41]. First are the ways techno-scientific futures manifest themselves in films. Films can be used as a starting point for analysis in order to examine the sociotechnical imaginaries expressed via cinematic images. Such analysis was conducted for this article. The second aspect incorporates the sociotechnical constellations and processes in which cinematic futures are generated. The starting point of analysis for this second perspective is not the films, but the contexts of their production and use. Drawing from Social Studies of Scientific Imaging and Visualization [42], such analysis should focus on the production, interpretation, distribution, and use of cinematic visions in order to explore their societal implications. Qualitative interpretive research methods are preferred for this investigation. The collection of Jasanoff and Kim [20] can serve as a conceptual and methodological template for both analytical perspectives. According to the authors in this collection, sociotechnical imaginaries can appear in individual objects and phenomena and are culturally produced and disseminated.

\section{Endnotes}

${ }^{1}$ For an overview of the literature that focuses on science and film, see also [43]. A vast body of literature in other disciplines, such as visual anthropology and visual sociology, also deals with broader questions of using film in cultural and social analyses. In this article, I focus on STS and science communication literature.
${ }^{2}$ The organizing university, Martin-Luther-Universität Halle-Wittenberg, is located in Halle, Saale, in eastern Germany. science2public, Gesellschaft für Wissenschaftskommunikation (Society for Science Communication), is a nonprofit organization based in the same city. Its main interest is "the advancement of the interdisciplinary dialog among science, politics, economy, and society" (www.science2public.com/about-us/motto/, retrieved June 16, 2018, translated by the author).ISI, located in Karlsruhe in southwestern Germany, is part of the academic Fraunhofer Society, which is Europe's largest applicationoriented research organization (www.fraunhofer.de/en/ about-fraunhofer/profile.html, retrieved June 16, 2018). ISI maintains numerous institutes and research establishments in Germany. ISI also incorporates Competence Center Foresight, which was a co-organizer of the festival.

${ }^{3}$ Such foresight processes have been practiced by the Ministry for more than 20 years. They are conducted in 2-year cycles that include different steps of (re)search and analysis, knowledge transfer, and preparation of the next cycle (www.bmbf.de/en/background-to-bmbf-foresight-1445.html (retrieved June 16, 2018). The aim of the foresight process, launched in 2012 and also called "the second foresight process," is to identify future societal challenges and trends [44-47].

${ }^{4}$ Media cooperation partners included Frankfurter Allgemeine Zeitung and the television stations ARTE and ZDF. In addition to the festival's website, a Facebook account was established (facebook.com/ForesightFilmfestival). Also, regular messages and updates were sent out from science2public's Twitter account (twitter.com/science2publicc).

${ }^{5}$ http://www.kultur-bildet.de/artikel/foresight-filmfestival-ndeg-1-call-entries (retrieved June 16, 2018). The award and prize money were not mentioned in all of the online published versions of the call. Also, in English versions of the call for entries, the maximum length was given as $15 \mathrm{~min}$.

${ }^{6} \mathrm{https} / / /$ science2media.de/academy-2015/ (retrieved June 16, 2018).

${ }^{7}$ http://foresight-filmfestival.de/archiv-2015/jury-2015/ (retrieved June 16, 2018). I was invited by the organizers to be a jury member.

${ }^{8}$ Instead of 15 films (five in each of the three categories), 16 films were selected by the jury to be considered for prizes because two films in the Artificial Intelligence category had received the same number of votes.

${ }^{9}$ With the exception of one film in the Post Privacy category, I did not choose the winning films for analysis because the winning films of the other two categories were based mainly on drawings and models and did not represent rich documents for this analysis. In addition, the winning films did not necessarily qualify as ones that express a prevalent sociotechnical imaginary based merely on the number of votes they received. The online 
votes were important but depended on the successful mobilization of families and friends. Some people may have voted multiple times online for their favorite film, so the number of votes did not necessarily match the number of voters.

${ }^{10}$ The website is www.enjoymalu.de (retrieved June 16, 2018). All citations from the website were translated from German to English by the author.

${ }^{11}$ foresight-filmfestival.de/portfolio/malu-2/ (retrieved June 4, 2015).

${ }^{12}$ The original word in German ["gemeinnütziges Projekt"] can be translated not only as "non-profit project" but also as a project that serves the public good. However, even in this latter reading, the subtext is similar; that is, in fact, the system is not serving the public good but rather the profit-driven data economy.

${ }^{13} \mathrm{http}: / / \mathrm{www} \cdot$ alexanderkalchev.com/greenpeace-new-bees/ (retrieved June 16, 2018).

${ }^{14} \mathrm{http}: / / w w w . a l e x a n d e r k a l c h e v . c o m / g r e e n p e a c e-n e w-b e e s /$ (retrieved June 16, 2018).

${ }^{15}$ sos-bees.org/causes/ (retrieved June 16, 2018).

\section{Abbreviations}

BMBF: Federal Ministry of Education and Research; ISI: Fraunhofer Institute for Systems and Innovation Research; STS: Science and technology studies;

TA: Technology Assessment; VDI: Verein Deutscher Ingenieure

\section{Acknowledgements}

I thank the organizers of the Foresight Filmfestival for inviting me to act as a member of the jury, which gave me the opportunity to gain knowledge about the festival films. I also thank the anonymous reviewers of this manuscript for their helpful and inspiring comments. My thanks also go to Cheryl Adam for proofreading the first draft, to Mary K. Brown for her careful editing of the final manuscript, and to Roberto Garbero, Springer Nature Open Research Group, for his support during the publishing process.

\section{Funding}

This research was conducted while the author was a member of HafenCity University (HCU) Hamburg and thus financially enabled by this institution. Travel expenses during the Foresight Filmfestival were covered by the organizers.

\section{Availability of data and materials}

All data analyzed during this study are publicly available. The internet links are included in this published article.

\section{Authors' contributions}

The author read and approved the final manuscript.

\section{Ethics approval and consent to participate}

Not applicable

\section{Consent for publication}

Not applicable (publicly available data)

\section{Competing interests}

The author declares that she has no competing interests.

\section{Publisher's Note}

Springer Nature remains neutral with regard to jurisdictional claims in published maps and institutional affiliations.
Received: 22 June 2018 Accepted: 18 September 2018

Published online: 03 October 2018

\section{References}

1. Cartwright $L$ (2015) Visual science studies: always already materialist. In: Carusi A, Hoel AS, Webmoor T, Woolgar S (eds) Visualization in the age of computerization. Routledge. New York, London, pp 243-268

2. Elena A (1997) Skirts in the lab: Madame Curie and the image of woman scientist in the feature film. Public Underst Sci 6(3):269-278

3. Fisher JA, Cottingham MD (2017) This isn't going to end well: fictional representations of medical research in television and film. Public Underst Sci 26(5):564-578

4. Haynes RD (2014) Whatever happened to the 'mad' 'bad' scientist? Overturning the stereotype. Public Underst Sci 25(1):31-44

5. Jensen $E$ (2008) The Dao of human cloning: utopian/dystopian hype in the British press and popular films. Public Underst Sci 17(2):123-143

6. Schmidt M, Meyer A, Cserer A (2015) The bio:fiction film festival: sensing how a debate about synthetic biology might evolve. Public Underst Sci 24(5):619-635

7. Terzian SG, Grunzke AL (2007) Scrambled eggheads: ambivalent representations of scientists in six Hollywood film comedies from 1961 to 1965. Public Underst Sci 16(4):407-419

8. Valenti JA (2015) Muddling through science at Sundance. Public Underst Sci 24(5):636-638

9. Van der Laan JM (2006) Machines and human beings in the movies. B Sci Technol Soc 26(1):31-37

10. Weingart P, Muhl C, Pansegrau P (2003) Of power maniacs and unethical geniuses: science and scientists in fiction film. Public Underst Sci 12(3):279-287

11. Landecker $\mathrm{H}$ (2012) The life of movement: from microcinematography to live-cell imaging. J Vis Cult 11(3):378-399

12. Shell HR (2012) Cinehistory and experiments on film. J Vis Cult 11(3): 288-306

13. Kirby DA (2003) Scientists on the set: science consultants and the communication of science in visual fiction. Public Underst Sci 12(3):261-278

14. Korsmo FL (2004) Shaping up planet earth: the international geophysical year (1957-58) and communicating science through print and film media. Sci Commun 26(2):162-187

15. Valenti JA (2014) Independent films communicating science at Sundance 2014. Public Underst Sci 23(6):750-752

16. Kirby DA (2011) Lab coats in Hollywood: science, scientists, and cinema. MIT Press, Cambridge MA

17. Levin LG, De Filippo D (2014) Films and science: quantification and analysis of the use of science fiction films in scientific papers. I Sci Commun 13(3):1-20

18. Van der Laan JM (2016) Movies, machines, and human beings. Narratives of technology. Palgrave Macmillan, Basingstoke, pp 187-202

19. Grin J, Grunwald A (2000) Vision assessment: shaping technology in 21 st century society. Towards a repertoire for technology assessment. Springer, Berlin

20. Jasanoff S, Kim SH (eds) (2015) Dreamscapes of modernity: sociotechnical imaginaries and the fabrication of power. The University of Chicago Press, Chicago

21. Messeri L, Vertesi J (2015) The greatest missions never flown: anticipatory discourse and the 'projectory' in technological communities. Technol Cult 56(1):54-85

22. Bina O, Mateus S, Pereira L, Caffa A (2017) The future imagined: exploring fiction as a means of reflecting on today's grand societal challenges and tomorrow's options. Futures 86:166-184

23. Hurley K (2008) Is that the future we want? An ecofeminist exploration of images of the future in contemporary film. Futures 40(4):346-359

24. Foresight Film Festival (2015a) Mit großer Zukunft: Das Foresight Filmfestival No1. Information sheet on the Foresight Film Festival, published by science2public, July 2, 2015, Halle (Saale)

25. Foresight Film Festival (2015b) Festival flyer. Foresight Film Festival, Halle (Saale)

26. Science2public (2015) Pressemitteilung: Wie wollen, wie werden wir leben? (press release). 03.07.2015. science2public, Halle (Saale)

27. Smith JK (2008) Interpretive Inquiry. In: Given LM (ed) The SAGE encyclopedia of qualitative research methods. Sage, Thousand Oaks CA, pp 460-461 
28. Felt U, Fouché R, Miller C, Smith-Doerr L (eds) (2017) The handbook of science and technology studies, 4th edn. MIT Press, Cambridge MA

29. Zeit online (2014) Google entwickelt Kontaktlinse für Diabetiker. Zeit online 17 Jan 2014.

30. Greenpeace (2014) Plan Bee - living without pesticides: moving towards ecological farming. Greenpeace International, Amsterdam

31. Jasanoff S (2015) Future imperfect: science, technology, and the imaginations of modernity. In: Jasanoff S, Kim SH (eds) Dreamscapes of modernity: sociotechnical imaginaries and the fabrication of power. The University of Chicago Press, Chicago, pp 1-33

32. Latour B (1987) Science in action: how to follow scientists and engineers through society. Harvard University Press, Cambridge MA

33. Bröckling U (2016) The entrepreneurial self: fabricating a new type of subject. Sage, London

34. Rose N (2007) Genomic susceptibility as an emergent form of life? Genetic testing, identity, and the remit of medicine. In: Burri RV, Dumit J (eds) Biomedicine as culture: instrumental practices, technoscientific knowledge, and new modes of life. Routledge, New York, London, pp 141-150

35. Owen R, Macnaghten P, Stilgoe J (2012) Responsible research and innovation: from science in society to science for society, with society. Sci Publ Policy 39(6):751-760

36. Rip A (2006) Folk theories of nanotechnologists. Sci Cult 15(4):349-365

37. Bourdieu P (1990) The logic of practice. Stanford University press, Stanford CA

38. Foucault M (2008) The birth of biopolitics: lectures at the Collège de France, 1978-79. Palgrave Macmillan, Houndmills, Basingstoke

39. Foucault M (2010) The government of self and others: lectures at the Collège de France, 1982-83. Palgrave Macmillan, New York

40. European Commission (2017) Attitudes of European citizens towards the environment. Special Eurobarometer 468, Wave EB88.1, October 2017. TNS political \& social, Brussels

41. Burri RV (2018) Filme in foresight- und TA-Analysen. TATuP 27(1):73-75

42. Burri RV, Dumit J (2008) Social studies of scientific imaging and visualization. In: Hackett E et al (eds) New handbook of science and technology studies. MIT Press, Cambridge MA, pp 297-317

43. Gouyon JB (2016) Science and film-making. Public Underst Sci 25(1):17-30

44. BMBF - Federal Ministry of Education and Research (2015) Zukunft verstehen, Zukunft gestalten. Deutschland 2030. Ergebnisse des zweiten Foresight-Zyklus. BMBF, Berlin

45. VDI Technologiezentrum (ed) (2015a) Gesellschaftliche Veränderungen 2030: Ergebnisband 1 zur Suchphase von BMBF-Foresight Zyklus II. VDI Technologiezentrum, Duesseldorf

46. VDI Technologiezentrum (ed) (2015b) Forschungs- und Technologieperspektiven 2030: Ergebnisband 2 zur Suchphase von BMBF-Foresight Zyklus II. VDI Technologiezentrum, Duesseldorf

47. VDI Technologiezentrum (ed) (2015c) Geschichten aus der Zukunft 2030 Ergebnisband 3 zur Suchphase von BMBF-Foresight Zyklus II. VDI Technologiezentrum, Duesseldorf

\section{Submit your manuscript to a SpringerOpen ${ }^{\circ}$ journal and benefit from:}

- Convenient online submission

- Rigorous peer review

- Open access: articles freely available online

- High visibility within the field

- Retaining the copyright to your article

Submit your next manuscript at $\boldsymbol{\nabla}$ springeropen.com 